\title{
PRODUÇÃO ACADÊMICA EM GESTÃO SOCIAL: VISITA AOS ANAIS DOS ENAPEGS DE 2007 A 2012
}

\author{
Edson Sadao Iizuka \\ Doutor em Administração Pública e Governo pela EAESP-FGV \\ Professor do Programa de Pós-Graduação em Administração - FEI/SP \\ esadao@fei.edu.br \\ Luciano Antônio Prates Junqueira \\ Doutor em Administração da Saúde pela Universidade de São Paulo \\ Professor Titular da Pontifícia Universidade Católica de São Paulo \\ junq@pucsp.br
}

\section{RESUMO}

Trata-se de um artigo que busca analisar a produção acadêmica com a temática da gestão social, especificamente o que foi produzido no âmbito do Encontro Nacional dos Pesquisadores em Gestão Social (ENAPEGS). Após vinte anos do início desta temática no Brasil, acredita-se na importância da análise do que já foi produzido em gestão social. Para isso, procedeu-se uma pesquisa bibliométrica dos artigos aprovados e apresentados nos encontros do ENAPEGS de 2007 (primeira edição deste evento) até 2012. Atualmente, o ENAPEGS é um dos principais congressos científicos na área social no Brasil. É neste evento que os principais pesquisadores interessados na gestão social lançam os seus questionamentos e as suas pautas de interesses. Foram analisados, neste estudo, um total de 434 artigos e, entre estes, selecionados 61 trabalhos (14\%) que apresentaram no título a expressão "gestão social". Os principais resultados da investigação entre as 1.284 referências bibliográficas sistematizadas foram os seguintes: 12 autores foram mencionados 10 vezes ou mais; 20 obras foram as mais citadas; a metodologia predominante foi a qualitativa. Além disso, verificou-se que os artigos concentram-se em seis temáticas - (i) educação, ensino e aprendizagem; (ii) gestão pública e políticas públicas; (iii) consórcios, cooperativas e redes; (iv) participação e negociação; (v) territórios e (vi) assistência social.

Palavras-chave: Bibliometria; Enapegs; Gestão social; Produção acadêmica.

\section{ACADEMIC PRODUCTION OF MANAGEMENT SOCIAL: VISIT THE ANNALS OF ENAPEGS 2007 TO 2012}

\begin{abstract}
This article analyzes academic productions with the theme of social management, specifically those produced under ENAPEGS, National Meeting of Researchers in Social Management. It has been twenty years since the conception of this issue in Brazil and we believe analysis of what has been produced in social management is important. For this, we carried out a bibliometric research study of the approved articles and presentations at meetings of ENAPEGS, 2007 (first edition of this event) until 2012. Currently, ENAPEGS is a major scientific conference in the social management field in Brazil. It is at this event that the principal researchers interested in social management discharge their questions and their patterns of interests. We analyzed a total of 434 articles and, of these, selected 61 papers (14\%) with the term "social management" in the title. The main results of the investigation were: among the 1284 references systematized, 12 authors were mentioned 10 times or more, 20 were the most cited works, the predominant methodology is qualitative, and the articles focus on six themes - (i) education, teaching and learning, (ii) public management and public policy, (iii) consortia, cooperatives, and networks, (iv) participation and negotiation, (v) territories (vi) and social assistance.
\end{abstract}

Key words: Academic production; Bibliometrics; Enapegs; Social management. 


\section{INTRODUÇÃO}

A gestão social tem se destacado como temática de trabalhos em diferentes ambientes acadêmicos ou mesmo de caráter profissional. Há quem questione a sua existência enquanto teoria, seja pela pertinência do próprio conceito (a gestão seria inevitavelmente social, dado que lida com pessoas), seja pela possibilidade de se constituir como área autônoma de conhecimento.

Embora se reconheça que exista um debate em construção, deve-se mencionar que é uma temática que vem ganhando espaço na agenda de diversos pesquisadores e até mesmo de profissionais dedicados à área social. Além disso, parece haver uma busca, pelos pesquisadores, por um caminho teórico mais sólido e robusto.

As discussões acerca da gestão social, com o sentido que se tem utilizado nas pesquisas atualmente, emergem em meio à transformação do papel do Estado no início da década de 1990. Desde então, passou-se de uma compreensão de que se tratava de um estilo de gestão das organizações do terceiro setor para uma discussão ampliada na qual foram incluídas as organizações públicas e privadas (Tenório, 2005).

Ao mesmo tempo em que a gestão social ganhava novos contornos, acompanhava-se uma articulação de um grupo de pesquisadores em busca de um espaço próprio e distinto aos que eram oferecidos no âmbito dos Encontros da Associação dos Programas de Pós-graduação em Administração Bibliometrics, (Enapegs), e em eventos temáticos da Anpad. Foi assim que se lançou o Enapegs, em 2007, na cidade de Juazeiro do Norte (CE).

Desde então, diversos pesquisadores têm-se reunido para analisar práticas comunitárias, experiências de interação da universidade com a sociedade, acompanhar debates e reflexões sobre a gestão social e assuntos correlatos. Diante disso, este estudo será orientado pelas seguintes questões de pesquisa: a) Quais as características da produção científica sobre gestão social apresentada no âmbito dos Enapegs? e b) Quais os temas tratados a respeito da gestão social? Acredita-se que fazer um balanço do que foi produzido sobre Gestão Social é algo necessário e, principalmente, útil no desenvolvimento de novas pesquisas, teses e dissertações sobre este assunto.

Cabe observar que a análise bibliométrica de estudos científicos é relevante para a comunidade acadêmica, pois: a) Indica a novos pesquisadores os temas já tratados; b) Verifica inconsistências na pesquisa realizada, tais como necessidades de estudos qualitativos ou quantitativos e c) permite identificar lacunas na teoria existente (Cooper; Lindsay, 1998). Além disso, reconhecem-se as bibliografias relevantes para estudos futuros, assim como permite observar as instituições que têm apresentado uma produção científica numa determinada área.

Assim, ao tentar responder as questões de pesquisa, busca-se ampliar as oportunidades para que outros pesquisadores possam agregar em suas agendas de pesquisa temas que ainda não foram suficientemente abordados ou ainda para que se aprofundem nas temáticas que já foram tratadas, repensem e até mesmo melhorem as metodologias utilizadas em suas pesquisas, atualizem-se quanto às bibliografias básicas sobre gestão social e, principalmente, que os interessados na temática façam reflexões sobre as suas potenciais contribuições no âmbito acadêmico.

Para cumprir com os objetivos deste artigo, além desta introdução, ele foi estruturado da seguinte forma: apresentar uma breve contextualização sobre a gestão social; em seguida, busca-se discutir a produção científica em gestão social; a partir disso, apresenta-se a metodologia de pesquisa bibliométrica a partir dos procedimentos de coleta de dados e, em seguida, parte-se para a discussão sobre os resultados. Finalmente, são apresentadas as considerações finais e as referências utilizadas na pesquisa.

\section{BREVE CONTEXTUALIZAÇÃO SOBRE A GESTÃO SOCIAL}

Os debates iniciais sobre gestão social no Brasil ocorreram a partir dos primeiros anos da década de 1990 e o foco de análise empírica se restringia às organizações do chamado terceiro setor. Em razão das proposições de alterações no papel do Estado ocorridas neste período - da gestão tecnocrática e gerencial para a gestão social - novas indagações emergiram entre 
pesquisadores. Assim, buscou-se um tipo de gestão que contemplasse a eficiência não só no planejamento como também na implantação de políticas sociais e na gestão de programas sociais (Tenório, 2009).

A temática da gestão social no Brasil evoluiu a partir de quatro momentos principais: inicialmente, foram localizadas e publicadas distintas e dispersas experiências de gestão nas quais se apresentavam a possibilidade de se alcançar objetivos sociais por meio do diálogo e da participação das pessoas; em seguida, tais experiências passam a ser reconhecidas e valorizadas como práticas relevantes de gestão; num terceiro momento, os pesquisadores passaram a considerar a gestão social como um campo de gestão particular (gestão participativa, gestão socialmente responsável, etc.) e, finalmente, apesar de não haver um consenso teórico sobre a gestão social, pode-se perceber que existe um processo de institucionalização e de modelização, por exemplo, nos cursos de pós-graduação lato e stricto sensu em gestão social (Boullosa e Schommer, 2009; Cançado, Tenório e Pereira, 2011).

Atualmente, pensar em gestão social significa preocupar-se com as novas formas participativas em organizações públicas, privadas e da sociedade civil, tal como descreveu Tenório (2009, p. 2): “[...] uma gestão ampliada na qual o processo decisório seria vinculante ao diálogo consciente, procedimental, por meios dos diferentes atores da sociedade, sob a perspectiva de sujeitos em ação". A gestão social ainda faz uma contraposição à chamada gestão estratégica, a qual é hegemônica no ensino, na pesquisa e prática da Administração (Tenório, 2009).

Dessa forma, a gestão social é uma forma de gestão que valoriza a concordância, em que o outro deve ser incluído e a solidariedade é a sua motivação. Além disso, a gestão social caracterizase por seu caráter coletivo, enquanto a gestão estratégica, pelo caráter individual, ou seja, baseado no monólogo e no indivíduo (Tenório, 2005).

Além disso, os teóricos que trabalham com a temática da gestão social parecem convergir para a importância de um processo de gestão que seja dialógico e transparente, no qual as pessoas se comunicam livremente em busca de consensos (Tenório, 2008; Fischer, 2002; Fischer; Melo, 2006; França Filho, 2008, entre outros).

Por outro lado, a despeito de se reconhecer diversas práticas relevantes em curso no país, é preciso mencionar que determinados pesquisadores tendem a questionar o próprio conceito de gestão social. Nesse sentido, Pinho (2010) argumentou que o termo "social" é convencional, indefinido e que pode encerrar ambiguidades. Além disso, o processo de participação, assim como os próprios espaços para que as pessoas possam se comunicar e exercer a sua cidadania, tais como os conselhos municipais, a formulação do orçamento participativo, entre outros, são escassos, limitados e até mesmo forjados e, portanto, a gestão social no Brasil é, salvo raras exceções, uma utopia (Pinho, 2010).

$\mathrm{Na}$ medida em que a gestão social se encontra em debate, os esforços no sentido de aperfeiçoamento da sua compreensão teórica e empírica são legítimos e relevantes.

\section{A PRODUÇÃO ACADÊMICA SOBRE GESTÃO SOCIAL}

Muito embora se reconheçam os debates teóricos que pairam sobre a temática, é preciso mencionar que em 2009, no âmbito dos Enanpads, a gestão social, assim como a gestão ambiental, não foi aceita como área de conhecimento, mas apenas como área de aplicação. Tal como a gestão hospitalar, percebe-se, no entanto, que a gestão social tem se apresentado, cada vez mais, em cursos de extensão, graduação, mestrado e doutorado. Ademais, reconhece-se a existência de periódicos dedicados à temática da gestão social, tais como os Cadernos de Gestão Social e a Revista Administração Pública e Gestão Social-APGS, entre outros. (Cançado et al, 2011).

Atualmente, um dos principais espaços para a discussão da temática da Gestão Social é o Enapegs. Desde 2007, pesquisadores, estudantes e membros da ONGs e de movimentos sociais, entre outras pessoas, têm se dedicado a compreender a gestão social e assuntos correlatos. Desde a 
primeira edição, é possível perceber um número crescente de pesquisadores, instituições e organizações da sociedade civil, assim como de artigos apresentados nos Enapegs.

Levantamento acerca de produção científica é uma prática presente em diferentes temáticas na área de gestão. Com relação à temática do terceiro setor, por exemplo, Iizuka e Sano (2004) e Paula et al (2010) realizaram as suas investigações, respectivamente, nos anais do Enanpad e em periódicos de alto impacto brasileiros. No campo da gestão pública no Brasil, Mezzomo Keinert (2000) buscou caracterizar os paradigmas da administração pública no Brasil, de acordo com o conceito de público. Para isso, foram analisados os artigos publicados entre 1937 e 1997 na Revista de Administração Pública (RAP) e na Revista do Serviço Público (RSP).

Em específico, no campo da gestão social, foram encontrados dois estudos bibliométricos. O primeiro foi desenvolvido por Cançado (2011) no âmbito de sua tese de doutorado. Este autor localizou 225 trabalhos cuja temática era a gestão social, sendo 40 teses/dissertações, 55 artigos em periódicos e 130 artigos em eventos. O segundo estudo foi apresentado por Cançado et al (2011) e se referia à produção científica nos Enapegs de 2007 a 2010. Um achado da pesquisa foi o de constatar que entre 2000 e 2003, nenhum artigo foi localizado no contexto do Enanpad, principal congresso acadêmico na área da Administração no Brasil. Em contrapartida, entre 2003 e 2005 foram localizados 155 artigos na área de gestão social e ambiental (Cançado, 2011).

Dessa forma, a pesquisa desenvolvida pode ser compreendida como um esforço adicional em sistematizar a produção acadêmica na temática da gestão social. Observando-se a evolução dos trabalhados apresentados nos Enapegs, constatou-se uma evolução expressiva no número de artigos, tal como se apresenta na Tabela 1.

Tabela 1 - Número de artigos

\begin{tabular}{c|c|c}
\hline \multicolumn{3}{c}{ Total de artigos nos ENAPEGS } \\
\hline 2007 & 12 & $2,76 \%$ \\
\hline 2008 & 21 & $4,84 \%$ \\
\hline 2009 & 13 & $3,00 \%$ \\
\hline 2010 & 125 & $28,80 \%$ \\
\hline $\mathbf{2 0 1 1}$ & $\mathbf{6 9}$ & $\mathbf{1 5 , 9 0 \%}$ \\
\hline $\mathbf{2 0 1 2}$ & $\mathbf{1 9 4}$ & $\mathbf{4 4 , 7 0 \%}$ \\
\hline & $\mathbf{4 3 4}$ & $\mathbf{1 0 0 , 0 0 \%}$ \\
\hline
\end{tabular}

Fonte: Anais dos Enapegs (2007, 2008, 2009, 2010, 2011 e 2012)

Ou seja, em torno de $70 \%$ dos artigos analisados no contexto dos Enapegs se concentraram nos anos de 2011 e 2012. Portanto, acredita-se na relevância deste estudo no sentido de atualizar e aprofundar o conhecimento sobre a produção científica na área da gestão social.

\section{MÉTODO DE PESQUISA}

Devido à limitação de tempo e recursos, foi decidido focalizar, nesta pesquisa, os anais dos Enapegs, referentes ao período compreendido entre 2007, $1^{\text {a }}$ edição do evento, até 2012, última edição, para efeitos deste artigo. Vale observar que o Enapegs tem se tornado, nos últimos anos, um ambiente cada vez mais consolidado e que tem reunido um conjunto de professores, pesquisadores, estudantes de graduação, mestrado e doutorado relevantes em temáticas relacionadas à gestão social no país.

A partir disso, fez-se um levantamento dos artigos via Internet, CD-ROM e também nos Anais publicados, de tal forma que se chegasse aos artigos que foram planejados nesta pesquisa. Ao todo, foram encontrados 61 artigos que tinham como temática principal a gestão social. Procedeuse, a partir de então, a leitura de cada um deles e montou-se um banco de dados com as principais informações colhidas nesses artigos.

A sistematização dos dados e das informações dos artigos selecionados permitiu, entre outras coisas, a verificação dos seguintes itens: a relação entre o número de artigos na temática 
gestão social e o total de artigos apresentados nos Enapegs; o referencial bibliográfico utilizado; as obras mais utilizadas pelos autores dos artigos; os autores que tiveram um maior número de menções nos trabalhos; a origem em termos institucionais dos artigos, assim como geográficos; as temáticas mais presentes nos artigos analisados e, finalmente, o tipo de metodologia de pesquisa utilizado.

A delimitação dos artigos selecionados para a análise foram os que apresentaram a gestão social mencionada no título do trabalho, ou seja, foram excluídos os artigos que mencionaram o assunto apenas como parte acessória à temática principal ou mesmo em algum argumento específico. Fez-se este tipo de escolha, pois, em geral, é a partir do título que os autores definem os conteúdos mais relevantes a serem apresentados ao longo do artigo.

Portanto, a estratégia de investigação utilizada, sob o enfoque qualitativo, foi inicialmente a revisão bibliográfica da literatura sobre gestão social e, em seguida, a pesquisa documental, pois foram analisados os artigos referentes à temática de gestão social aprovados no âmbito dos Enapegs. Nesse contexto, Moreira (2005) salienta que a pesquisa documental caracteriza-se como processo de levantamento, verificação e interpretação de documentos, tendo como objetivo um fim predeterminado que, conforme observam Lakatos e Marconi (1990), pode ser efetuada ao longo dos anos, pois as informações estarão arquivadas nos referidos documentos.

Finalmente, cabe observar que foi utilizada, sob o enfoque quantitativo, a estatística descritiva simples dos artigos de acordo com as variáveis: artigos em que o título revelava foco na temática da gestão social; instituição de ensino do autor principal; autoria; localização geográfica; método utilizado.

\section{APRESENTAÇÃO E ANÁLISE DOS RESULTADOS}

Considerando-se as seis edições do Enapegs, foi localizado um total de 434 artigos. Destes, 61 trabalhos apresentaram em seus títulos a expressão "gestão social", que foi utilizada como indicativo de foco nesta temática, dado que o título expressa, em geral, os conceitos principais do artigo. Tendo em vista os percentuais em cada uma das edições do Enapegs, obteve-se uma média $16 \%$ de artigos com a temática da gestão social, conforme Tabela 2.

Tabela 2 - Quantidade de artigos focados na temática gestão social

\begin{tabular}{l|c|c}
\hline \multicolumn{2}{c|}{ Artigos - Tema Gestão Social } & Percentual \\
\hline 2007 & 7 & $11,48 \%$ \\
\hline 2008 & 6 & $9,84 \%$ \\
\hline 2009 & 5 & $8,20 \%$ \\
\hline 2010 & 12 & $19,67 \%$ \\
\hline 2011 & 10 & $16,39 \%$ \\
\hline 2012 & 21 & $34,43 \%$ \\
\hline
\end{tabular}

Fonte: Anais dos Enapegs (2007, 2008, 2009, 2010, 2011 e 2012)

Ou seja, em $84 \%$ dos artigos apresentados nas edições dos Enapegs, outros assuntos emergiram, tais como economia solidária, empreendedorismo social, políticas públicas, sustentabilidade, responsabilidade social das empresas, entre outros assuntos. Isso tende a revelar que os pesquisadores que participaram dos Enapegs têm apresentado uma variedade de temas e interesses. Essa diversidade temática pode significar o resultado de uma postura mais inclusiva deste evento científico, ao mesmo tempo em que parece apontar para um campo de conhecimento em processo inicial de construção.

Em relação à autoria das pesquisas, houve um predomínio de autores que apresentaram individualmente os seus trabalhos (34\%) e, em seguida, a presença de dois autores foi observada em $29 \%$ dos artigos analisados. Num outro extremo, trabalhos com cinco autores ocorreram em pouco mais de $6 \%$ dos artigos, ou seja, em termos absolutos, quatro pesquisas, conforme Tabela 3. 
Tabela 3 - Quantidade de autores por artigo

\begin{tabular}{l|c|c}
\hline \multicolumn{3}{c}{ Por número de autor(es) } \\
\hline 1 & 21 & $34,43 \%$ \\
\hline 2 & 18 & $29,51 \%$ \\
\hline 3 & 11 & $18,03 \%$ \\
\hline 4 & 7 & $11,48 \%$ \\
\hline 5 & 4 & $6,56 \%$ \\
\hline
\end{tabular}

Fonte: Anais dos Enapegs $(2007,2008,2009,2010,2011$ e 2012)

A predominância de artigos com um único autor parece apontar para um quadro em que a produção científica, no contexto dos Enapegs, tem ocorrido, sobretudo, a partir de esforços isolados, sem o respaldo de equipes de pesquisa. Em contrapartida, os trabalhos com dois ou mais autores (em torno de 65\%) podem significar que os pesquisadores têm trabalhado de forma coletiva no contexto de equipes de pesquisa ou centros de estudo.

Analisando-se a produção científica e as IESs de origem, foi possível perceber uma quantidade considerável de universidades e faculdades - 28 IESs em seis edições do Enapegs. É preciso considerar a concentração dos artigos entre as 10 IESs que mais apresentaram artigos: $77 \%$ do total. Tal resultado corresponde ao que era esperado, pois nestas IESs existe uma tradição de pesquisas nesta temática e, em algumas delas, há a presença de centros de estudos e pesquisas consolidadas, por exemplo, o Centro Interdisciplinar de Desenvolvimento e Gestão Social, (Ciags) da UFBA, o grupo de pesquisas vinculadas aos programas de mestrado e doutorado da UFLA e da Ebape-FGV, o grupo de estudos e pesquisa em Gestão Social da PUC-SP e, finalmente, a expressiva presença da UFC e da UFC campus Cariri pode ser explicada pela presença de pesquisadores e estudantes que têm se dedicado à temática da gestão social ao longo dos últimos anos. E isso está expresso na Tabela 4.

Tabela 4 - Quantidade de artigos por IES

\begin{tabular}{l|c|l|l}
\hline \multicolumn{4}{|c}{ Artigos por IES } \\
\hline UFBA-BA & 10 & EAESP-FGV - SP & 1 \\
\hline UFLA-MG & 7 & FURB - SC & 1 \\
\hline UFC - Cariri - CE & 6 & PUC-MG & 1 \\
\hline PUC-SP & 5 & UFAL - AL & 1 \\
\hline EBAPE-FGV - RJ & 4 & UFERSA - RN & 1 \\
\hline UFC - CE & 4 & UFRN - RN & 1 \\
\hline FECAP - SP & 3 & UFRRJ - RJ & 1 \\
\hline UNA - MG & 3 & UFSC - SC & 1 \\
\hline UNIJUI - RS & 3 & UFT - TO & 1 \\
\hline UDESC - SC & 2 & FAAP - SP & 1 \\
\hline UFPB - PB & 2 & UFMG - MG & 1 \\
\hline UFRGS - RS & 2 & UNICAMP - SP & 1 \\
\hline UFSJ - MG & 2 & UNESA - RJ & 1 \\
\hline UFV - MG & 2 & UMESP - SP & 1 \\
\hline
\end{tabular}

Fonte: Anais dos Enapegs (2007, 2008, 2009, 2010, 2011 e 2012)

Por outro lado, a diversidade de IES pode indicar, entre outros, que a gestão social tem emergido como temática nestas instituições de ensino, assim como parece apontar para uma área que se encontra no início de sua estruturação científica. Com relação aos Estados e Regiões brasileiras, os resultados obtidos apontaram uma predominância da produção científica em sete Estados da federação, quais sejam: MG, BA, CE, SP, RJ, RS e SC. Tal fato está correlacionado à localização das IESs dos autores dos artigos, tal como se apresenta na Tabela 5. 
Tabela 5 - Quantidade de artigos por Estado

\begin{tabular}{c|c|c}
\hline \multicolumn{3}{|c}{ Artigos por Estado } \\
\hline MG & 15 & $23,08 \%$ \\
\hline BA & 10 & $15,38 \%$ \\
\hline CE & 10 & $15,38 \%$ \\
\hline SP & 10 & $15,38 \%$ \\
\hline RJ & 6 & $9,23 \%$ \\
\hline RS & 5 & $7,69 \%$ \\
\hline SC & 4 & $6,15 \%$ \\
\hline PB & 2 & $3,08 \%$ \\
\hline AL & 1 & $1,54 \%$ \\
\hline RN & 1 & $1,54 \%$ \\
\hline TO & 1 & $1,54 \%$ \\
\hline
\end{tabular}

Fonte: Anais dos Enapegs (2007, 2008, 2009, 2010, 2011 e 2012)

Em uma segunda sistematização da regionalidade, foi possível constatar que a produção científica dos Enapegs se concentra nas regiões sudeste $(47,7 \%)$ e nordeste (37\%). A região norte contribuiu com 1,5\% (1 artigo) do total de artigos; não se verificou artigos produzidos na região centro-oeste do país. Ou seja, a pesquisa sobre a produção científica em gestão social a partir dos Enapegs revelou um quadro de desequilíbrio sob a ótica geográfica.

A pesquisa apontou um predomínio do uso das metodologias qualitativas nos artigos apresentados nos Enapegs (70,5\%). A sistematização das bibliografias, a partir da revisão bibliográfica e as análises de experiências e projetos por meio de estudos de caso, análise de discurso se apresentaram como as principais técnicas qualitativas. Além disso, se destacou a presença de ensaios teóricos (23\%), algo que corresponde a uma área científica que está em construção. Com relação aos métodos quantitativos $(6,5 \%)$, foi possível observar testes estatísticos de hipóteses e a análise de redes. A Tabela 6 sintetiza as informações apresentadas.

Tabela 6 - Metodologias de pesquisa

\begin{tabular}{|l|c|c|}
\hline \multicolumn{3}{|c|}{ Metodologias utilizadas } \\
\hline Qualitativas & 43 & $70,49 \%$ \\
\hline Quantitativas & 4 & $6,56 \%$ \\
\hline Ensaio Teórico & 14 & $22,95 \%$ \\
\hline
\end{tabular}

Fonte: Anais dos Enapegs (2007, 2008, 2009, 2010, 2011 e 2012)

A investigação dos artigos incluiu as temáticas que os autores apresentaram ao longo dos seis anos de Enapegs. Num esforço de síntese, perceberam-se seis temáticas principais: (i) Educação, ensino e aprendizagem; (ii) Assistência social; (iii) Gestão Pública e Políticas Públicas; (iv) Territórios; (v) Consórcios, Cooperativas e Redes e, finalmente, (vi) Participação e Negociação. Essas temáticas parecem indicar quais são os assuntos mais relevantes, neste momento, no campo da gestão social. Isso não exclui outras possibilidades de pesquisa, mas apenas aponta as temáticas sobre as quais os pesquisadores têm empreendido seus esforços. A figura 1 reúne as temáticas e os subtemas presentes nos artigos analisados.

\section{Educação, ensino, aprendizagem - 19 artigos}

Aprendizagem Profissional; Ensino; Percepção Docente; Programas Stricto Sensu; Educação; Cursos de Administração; Aprendizagem; Programa de Estudos (PEGS); Metodologias Não-Convencionais; Formação; Ensino e Pesquisa; Academia-Sociedade; Metodologias de Aprendizagem.

\section{Gestão Pública e Políticas Públicas - 10 artigos}

Políticas Públicas; Gestão Pública; Desenvolvimento Local; Gestão Pública; Bens Culturais; Gestão Pública Societal; Cultura Política; Desenvolvimento Rural; Política Pública Local; Saúde Pública e Inovação; Habitação. 


\section{Territórios -6 artigos}

Desenvolvimento Territorial Sustentável; Governança Territorial; Território e Território da Cidadania.

\section{Assistência Social -5 artigos}

Portadores de Deficiência e Mercado de Trabalho; Assistência Social; Programa de Atenção Integral à Família.

\section{Consórcios, Cooperativas e Redes -5 artigos}

Consórcios; Cooperativas Agropecuárias; Rede e Terceiro Setor; Redes de Colaboração Científica; Rede Solidária; Redes Empresariais e Desenvolvimento Local.

\section{Participação e negociação - 3 artigos}

Negociação e Participação; Gestão Social Urbana; Cidadania Deliberativa; Moradia Estudantil; Fórum Social Mundial e Participação.

\section{Outros temas - 13 artigos}

Cooperativas Agropecuárias; Teoria da Estruturação; Reserva Extrativista; Economia/Finanças Solidária; Gestão Estratégica; Cultura Política; Gestor social; Sustentabilidade Empresarial; Empreendimento Econômico Solidário; Definições do conceito de gestão social.

Figura 1 - Temas e subtemas de pesquisa

Fonte: Anais dos Enapegs (2007, 2008, 2009, 2010, 2011 e 2012)

Para compreender quais são as tendências temáticas no campo da gestão social, apresentamse os artigos, com os respectivos temas, entre os anos de 2007 e 2012 na Tabela 7:

Tabela 7 - Temas e subtemas de pesquisa ao longo do tempo

\begin{tabular}{l|c|c|c|c|c|c|c}
\cline { 2 - 7 } & $\mathbf{2 0 0 7}$ & $\mathbf{2 0 0 8}$ & $\mathbf{2 0 0 9}$ & $\mathbf{2 0 1 0}$ & $\mathbf{2 0 1 1}$ & $\mathbf{2 0 1 2}$ & TOTAL \\
\hline Educação, ensino e aprendizagem & 4 & 3 & 1 & 3 & 1 & 7 & $\mathbf{1 9}$ \\
\hline Gestão Pública e Políticas Públicas & 0 & 0 & 1 & 5 & 2 & 2 & $\mathbf{1 0}$ \\
\hline Territórios & 0 & 0 & 0 & 1 & 2 & 3 & $\mathbf{6}$ \\
\hline Assistência Social & 0 & 1 & 0 & 2 & 0 & 2 & $\mathbf{5}$ \\
\hline Consórcios, Cooperativas e Redes & 0 & 2 & 0 & 0 & 2 & 1 & $\mathbf{5}$ \\
\hline Participação e negociação & 0 & 0 & 2 & 0 & 0 & 1 & $\mathbf{3}$ \\
\hline Outros temas & 3 & 0 & 1 & 1 & 3 & 5 & $\mathbf{1 3}$ \\
\hline \multicolumn{1}{c}{ TOTAL } & $\mathbf{7}$ & $\mathbf{6}$ & $\mathbf{5}$ & $\mathbf{1 2}$ & $\mathbf{1 0}$ & $\mathbf{2 1}$ & $\mathbf{6 1}$ \\
\hline
\end{tabular}

Fonte: Anais dos Enapegs (2007, 2008, 2009, 2010, 2011 e 2012)

$\mathrm{Na}$ temática "educação, ensino e aprendizagem", o mais tradicional e frequente tema de pesquisa sobre gestão social, encontraram-se artigos, tais como o ensaio teórico de Schommer e França Filho (2007) sobre "Gestão social e aprendizagem em comunidades de prática: interações conceituais e possíveis decorrências em processo de formação"; o trabalho de Ramos et al (2009) no qual discorreram sobre "Importância percebida e intenções de envolvimento com a gestão social: uma análise junto a estudantes de cursos de Administração" e o artigo de Borges et al (2008) acerca do "Ensino e pesquisa em administração e gestão social: uma experiência de interação academiasociedade". Pode-se perceber, por meio dos artigos analisados, que as experiências desenvolvidas no âmbito das Universidades apresentaram-se como relevantes nas pesquisas, ou seja, os locais de atuação dos pesquisadores serviram como meios de investigação aos que se dedicaram à temática de educação, ensino e aprendizagem. De fato, tal temática tem despertado a atenção dos pesquisadores, não apenas no campo da gestão social, mas de outras áreas, tais como o empreendedorismo (Iizuka e Moraes, 2013).

$\mathrm{O}$ segundo tema mais frequente associado à gestão social e que se apresentou como relevante aos pesquisadores dessa campo do conhecimento foi a da "gestão pública e políticas públicas". O ensaio teórico de Barros e Castro (2011) no qual abordaram a "Gestão social e gestão pública no desenvolvimento local" e o trabalho de Freitas, Freitas e Dias (2010) em que trataram a "Gestão social e políticas públicas: uma mudança de abordagem no desenvolvimento rural" são ilustrativos neste recorte temático. Conforme os artigos analisados, os pesquisadores privilegiaram 
os aspectos locais e as demandas que emergiram e se legitimaram entre os cidadãos, ou seja, um processo botton-up das políticas públicas. Num país continental como o Brasil, este tema parece ser algo relevante para o avanço na gestão pública rumo a uma maior sintonia com as expectativas dos cidadãos. De acordo com os dados sobre a produção entre 2007 e 2012, parece que tal temática tende a se expandir nos próximos anos.

O terceiro tema mais frequente englobaram os artigos que trataram dos fenômenos relacionados aos "territórios". Exemplificam esse tipo de artigo os que foram desenvolvidos por Bauer e Carrion (2010), intitulado "Gestão social do território: entre a ideologia e a utopia", e Pinheiro Callou e Alves (2012), com "Uma visão de governança territorial inspirada em princípios de gestão social". Seja no mundo acadêmico, seja na prática de políticas públicas, a questão territorial parece estar cada vez mais presente na agenda e aponta uma temática sobre a qual seja possível ampliar as investigações. Conforme dados obtidos, pode-se perceber que se trata, provavelmente, de uma temática crescente entre os pesquisadores dedicados à gestão social no Brasil. Sendo assim, espera-se que exista um aumento no volume de produções acadêmicas que tratem da gestão social e do território.

A atenção em relação à "assistência social" foi percebida em artigos, tais como o de Reis e Melo (2012), no qual discorreram sobre a "Participação dos atores em um fórum de gestão social para a inserção de pessoas com deficiência no mercado de trabalho: uma análise a partir das atas", e de Muniz, Onuma e Pereira (2010), em quem os autores apresentaram o artigo "A gestão social do programa de atenção integral à família em Lavras - MG". Trata-se de uma temática tradicional no campo das políticas públicas, em especial das políticas sociais, e que no contexto dos pesquisadores em gestão social tem ganhado contornos a partir da análise da participação de atores desde a concepção das iniciativas e até mesmo no processo de implementação das propostas. Assim, trata-se de uma temática atual e com espaço para novas pesquisas.

Além disso, a temática "consórcios, cooperativas e redes" foi verificada entre os diversos artigos analisados. Entre eles, citam-se o artigo de Vinha e Junqueira (2011) denominado "A gestão social de uma rede do terceiro setor: o caso da rede sementeira", e o trabalho de Villela (2008), no qual discorreu sobre as "Redes empresariais como germe da gestão social e do desenvolvimento local: o caso de Nova Friburgo/RJ”. A atuação coletiva, a partir de consórcios, cooperativas e redes, é uma das opções promissoras em trabalhos futuros, na medida em que há uma variedade de experiências desse gênero no Brasil.

Finalmente, notou-se que o tema "participação e negociação" apresentou-se com relativo destaque entre os artigos analisados. Podem-se citar os seguintes trabalhos: a pesquisa de Mendes (2012) sobre a "Gestão social urbana: negociação e participação de seus habitantes" e o artigo de Iizuka (2012) intitulado como "Fluxo de ações, a gestão social e o processo decisório: a experiência da creche noturna em Laranjal Paulista - SP" como exemplos de trabalhos que se encontram nesta temática. Da mesma forma que as políticas públicas no estilo botton up, tal perspectiva de análise se apresenta como possibilidade relevante aos pesquisadores, especialmente porque se trata de um dos requisitos principais para as experiências investigadas no campo da gestão social.

Após percorrer as principais temáticas presentes nos artigos dos Enapegs, apresentam-se as análises sobre os autores mais citados nos trabalhos, assim como as obras que foram mencionadas em maior quantidade nos artigos. A tabela 8 apresenta os autores mais citados nos 61 artigos pesquisados.

Tabela 8: Autores mais citados

\begin{tabular}{l|c}
\hline Autores mais citados (10 ou mais citações) & Citações \\
\hline 1. TENÓRIO, Fernando Guilherme. & 83 \\
\hline 2. FRANÇA FILHO, Genauto Carvalho de. & 35 \\
\hline 3. FISCHER, Tânia. & 21 \\
\hline 4. HABERMAS, Jürgen. & 16 \\
\hline 5. DOWBOR, Ladislau & 13 \\
\hline
\end{tabular}




\begin{tabular}{l|c}
\hline 6. BOULLOSA, Rosana F. & 12 \\
\hline 7. SEN, Amartya. & 11 \\
\hline 8. SCHOMMER, Paula Chies. & 11 \\
\hline 9. SANTOS, Boaventura de Sousa. & 11 \\
\hline 10. PAES DE PAULA, Ana Paula. & 10 \\
\hline 11. LEITÃO, Sérgio Proença. & 10 \\
\hline 12. BOURDIEU, Pierre. & 10 \\
\hline
\end{tabular}

Fonte: Anais dos Enapegs (2007, 2008, 2009, 2010, 2011 e 2012)

Pode-se perceber que autores considerados clássicos, tais como Habermas, Santos, Bourdieu e Sen se misturaram a autores tradicionais, tais como Tenório, França Filho e Fischer, Dowbor e autores mais jovens e em ascendência, tais como Boullosa, Schommer e Paes de Paula. Seja como for, tratam-se de autores relevantes, neste momento, em relação aos pesquisadores em gestão social no Brasil. Isso não significa que outros autores possam ser incluídos em pesquisas futuras. Contudo, os trabalhos apresentados nos Enapegs foram úteis no sentido de se verificar, afinal, quem são os autores chaves no campo da gestão social.

Em relação às obras mais utilizadas, é preciso apontar que ao todo, sistematizaram-se 1.284 referências a partir dos 61 artigos analisados. A partir deste momento, foram observadas as obras que se apresentaram com maior frequência e chegou-se ao que está apresentado figura 2.

\begin{tabular}{|c|c|c|c|}
\hline & Obras mais citadas & Autor(es) & Menções \\
\hline 1 & $\begin{array}{l}\text { Definindo gestão social. In: Silva Jr, J. T.; Mâsih, R. T.; Cançado, A. C.; } \\
\text { Schommer, P. C. (Orgs.). Gestão social: práticas em debate, teorias em construção. } \\
\text { Fortaleza: Imprensa Universitária, 2008. }\end{array}$ & $\begin{array}{l}\text { França Filho, } \\
\text { G. C. }\end{array}$ & 17 \\
\hline 2 & $\begin{array}{l}\text { (Re)visitando o conceito de gestão social. Desenvolvimento em Questão, v. 5, p. } \\
\text { 101-124, } 2005 .\end{array}$ & Tenório, F. & 15 \\
\hline 3 & $\begin{array}{l}\text { Um espectro ronda o terceiro setor, o espectro do mercado: ensaios sobre a } \\
\text { gestão social. } 2 \text { ed. Ijuí: Editora Unijuí, } 2004 .\end{array}$ & Tenório, F. & 8 \\
\hline 4 & Desenvolvimento como liberdade. São Paulo: Cia. das Letras, 2005. & Sen, A.K. & 7 \\
\hline 5 & $\begin{array}{l}\text { Gestão social: uma perspectiva conceitual. Revista de Administração Pública, } \\
\text { Rio de Janeiro, v. 32, n. 5, p. 7-23, set./out. } 1998 .\end{array}$ & Tenório, F. & 7 \\
\hline 6 & $\begin{array}{l}\text { Administração pública brasileira: entre o gerencialismo e a gestão social. } \\
\text { Revista de Administração de Empresas, v. } 45, \text { n.1, jan./mar. } 2005 .\end{array}$ & $\begin{array}{l}\text { Paes De Paula, } \\
\text { A. }\end{array}$ & 6 \\
\hline 7 & Tem razão a administração? 3 Ed. Ijuí: Editora da Unijuí, 2008. & Tenório, F. & 6 \\
\hline 8 & $\begin{array}{l}\text { Limites da natureza da inovação ou qual o futuro da gestão social? Anais do } \\
\text { XXXII Enanpad - Encontro Nacional de Pós-Graduação (...). RJ: Anpad, } 2008 .\end{array}$ & $\begin{array}{l}\text { Boullosa e } \\
\text { Schommer }\end{array}$ & 5 \\
\hline 9 & $\begin{array}{l}\text { Gestão social: um conceito em construção. In: Colóquio Internacional sobre } \\
\text { Poder Local, } 9 \text {, jun. de 2003, Salvador. Anais do IX Colóquio(...), Salvador, } 2003 .\end{array}$ & $\begin{array}{l}\text { França Filho, } \\
\text { G. C. }\end{array}$ & 5 \\
\hline 10 & $\begin{array}{l}\text { Gestão social e aprendizagem em comunidades de prática: interações } \\
\text { conceituais e possíveis decorrências em processos de formação. In. SILVA JR, } \\
\text { J. T.; MÂSIH, R. T.; et al. Gestão Social: práticas (...). Fortaleza: Imprensa Univ., } \\
\text { 2008. }\end{array}$ & $\begin{array}{l}\text { Schommer, P.; } \\
\text { França Filho, } \\
\text { G.C. }\end{array}$ & 5 \\
\hline 11 & Gestão social, metodologia e casos. Rio de Janeiro: FGV, 2003. & Tenório, F. & 5 \\
\hline 12 & Cidadania e desenvolvimento local. RJ, FGV, Editora Unijuí. 2007 & Tenório, F. & 5 \\
\hline 13 & $\begin{array}{l}\text { Direito e democracia: entre a facticidade e validade. Rio de Janeiro, Tempo } \\
\text { Brasileiro, } 1997 .\end{array}$ & Habermas, J. & 4 \\
\hline 14 & $\begin{array}{l}\text { Gestão social: uma réplica. ADM.Made., ano 9, v.13, n.2, p.1-4, maio/agosto, } \\
2009 .\end{array}$ & Tenório, F. & 4 \\
\hline 15 & $\begin{array}{l}\text { A gestão social em busca de paradigmas. In: Rico, E. M.; Raichelis, R. (Orgs.). } \\
\text { Gestão Social: uma questão em debate. SP: Educ/IEE/PUCSP, 1999. p. 31-42. }\end{array}$ & Dowbor, L. & 3 \\
\hline
\end{tabular}

Revista de Gestão Social e Ambiental - RGSA, São Paulo, v. 6, n. 3, p. 71-85, maio/ago. 2013. 


\begin{tabular}{|c|c|c|c|}
\hline 16 & $\begin{array}{l}\text { Gestão social e transformação da sociedade. In: Arbix, Glauco; Zilbovicius, } \\
\text { Mauro; Abramovay, Ricardo. Razões e ficções do desenvolvimento. São Paulo: } \\
\text { Editora UNESP; Edusp, 2001. p. 197-221. }\end{array}$ & Dowbor, L. & 3 \\
\hline 17 & $\begin{array}{l}\text { Gestão do desenvolvimento e poderes locais: marcos teóricos e } \\
\text { avaliação.Salvador, BA. Casa da Qualidade, } 2002 .\end{array}$ & Fischer, T. & 3 \\
\hline 18 & $\begin{array}{l}\text { Mudança estrutural da esfera pública: investigações quanto a uma categoria } \\
\text { da sociedade burguesa. Rio de Janeiro: Tempo Brasileiro, } 2003 .\end{array}$ & Habermas, J. & 3 \\
\hline 19 & $\begin{array}{l}\text { O poder no contexto da decisão organizacional. Rio de Janeiro: Revista de } \\
\text { Administração Pública, } 30 \text { (2), p. 137-151, } 1996 .\end{array}$ & Leitão, S. P. & 3 \\
\hline 20 & $\begin{array}{l}\text { Por uma nova gestão pública: limites e potencialidades da experiência } \\
\text { contemporânea. Rio de Janeiro, Ed. FGV, } 2005 .\end{array}$ & $\begin{array}{l}\text { Paes De Paula, } \\
\text { A. }\end{array}$ & 3 \\
\hline
\end{tabular}

Figura 2 - Obras mais citadas

Fonte: Anais dos Enapegs (2007, 2008, 2009, 2010, 2011 e 2012)

As obras apresentadas podem ser consideradas como relevantes aos pesquisadores em gestão social. Aos iniciantes, em particular, considera-se como uma literatura quase que obrigatória. Neste contexto, as duas obras mais citadas "Definindo gestão social" e "(Re)visitando o conceito de gestão social", de França Filho (2008) e Tenório (2005), respectivamente, são relevantes no sentido de compreender, de forma inicial, a gestão social. Acredita-se que esta lista possa ser útil no avanço e amadurecimento dos trabalhos futuros na temática.

\section{CONSIDERAÇÕES FINAIS}

Esta pesquisa teve como objetivo analisar a produção científica a partir dos artigos apresentados nos Enapegs. Nesse sentido, é válido retomar as questões de pesquisa que guiaram esse estudo: a) Quais as características da produção científica sobre gestão social apresentada no âmbito dos Enapegs? e b) Quais os temas tratados a respeito da gestão social? Pode-se concluir o seguinte: que a pesquisa sobre gestão social encontra-se atualmente em um estágio inicial, de pesquisa pontual, relativamente dispersa em termos temáticos e com lacunas a serem exploradas. Embora isso seja comum para um tema recente e de fronteira como a gestão social, há oportunidades para o estabelecimento de redes de pesquisadores e a sua estruturação em linhas de pesquisa concretas, que preencham temas de fronteira na literatura com pesquisas mais robustas e com vistas aos resultados de médio e longo prazo.

A temática relacionada à educação, ensino e aprendizagem se mostrou mais frequente, o que indica que se trata de um assunto tradicional entre os pesquisadores da área de gestão social; duas temáticas se apresentaram como promissoras em pesquisas futuras, na medida em que houve um aumento no número de artigos gestão pública/políticas públicas e territórios. Nesse sentido, a partir da análise temática, foi possível perceber uma ampla diversidade de temas tratados pelos pesquisadores. Por um lado, isso é reflexo dos diferentes interesses individuais sobre a gestão social. Por outro, pode revelar a falta de linhas de pesquisa consistentes que tratem da gestão social de forma constante no tempo.

Em contraste à diversidade de temas, os métodos de pesquisa nos artigos analisados são majoritariamente qualitativos. Muito embora se reconheça a importância das metodologias qualitativas, sobretudo em estudos na área social, a pesquisa apontou uma carência de trabalhos que façam o uso de técnicas quantitativas. E esta lacuna é um convite para que os pesquisadores incrementem suas pesquisas com técnicas de investigação em que os números e a estatística façam parte dos esforços em busca de novas contribuições na área da gestão social.

Neste contexto, provavelmente, as pesquisas se limitaram a fase exploratória, não evoluindo para a construção de estudos de natureza explicativa, o que provoca, muito provavelmente, a descontinuidade dos temas que são desenvolvidos nos estudos da área. Contudo, como em outras áreas da administração, o número de artigos teórico-empíricos que utilizam métodos quantitativos e 
multimétodos pode vir a aumentar nos próximos anos e isso, em princípio, pode contribuir no amadurecimento neste campo de conhecimento.

Considerando-se as 10 IESs mais produtivas, temos 77\% dos artigos da área produzidos por elas, o que indica que a produção na área encontra-se centralizada em poucas instituições. A partir da décima instituição listada, verifica-se que a publicação científica é bastante pulverizada, dado que o número de instituições é elevado se comparado ao número de trabalhos apresentados nos Enapegs. Nesse sentido, parece haver um desafio concreto no sentido de se ampliar e fortalecer a produção científica em gestão social no país, sobretudo nas regiões norte e centro-oeste.

A principal limitação da pesquisa se refere ao universo pesquisado, limitado aos Enapegs. Analisar a produção científica em teses, dissertações e artigos publicados em periódicos, nacionais e internacionais, se faz necessária para que as conclusões sejam ampliadas e fortalecidas. No entanto, acredita-se ter contribuído no sentido de buscar achados que pudessem colaborar, desde já, com os pesquisadores e demais envolvidos com a gestão social.

\section{REFERÊNCIAS}

Barros, A.A. de., Castro, H.S. de.(2011) Gestão social e gestão pública no desenvolvimento local. In: Encontro Nacional de Pesquisadores em Gestão Social, 5, Florianópolis (SC). Anais....

Bauer, M.A.L., Carrion, R.M.(2010) Gestão social do território: entre a ideologia e a utopia. In: Encontro Nacional de Pesquisadores em Gestão Social, 4, Lavras (MG). Anais....

Borges, A.C.V., et al.(2008) Ensino e pesquisa em administração e gestão social: uma experiência de interação academia-sociedade. In: Encontro Nacional de Pesquisadores em Gestão Social, 2, Palmas (TO). Anais....

Botrel, M. de O., Araújo, P.G. de., Pereira, J.R. (2010) Entre a gestão pública e a gestão social de bens culturais no Brasil. In: Encontro Nacional de Pesquisadores em Gestão Social, 4, Lavras (MG). Anais....

Boullosa, R. F., Schommer, P. C.(2009) Gestão social: caso de inovação em políticas públicas ou mais um enigma de lampedusa? In Encontro Nacional de Pesquisadores em Gestão Social, 3, Juazeiro/Petrolina. Anais..., Juazeiro/Petrolina: Nigs/Univasf. 1 Cd Rom.

Cançado, A.C., Tenorio, F.G., Pereira, J.R.(2011) Gestão social: reflexões teóricas e conceituais. Cad. Ebape.BR, Rio de Janeiro , 9(3), Sept. Recuperado em: 22 nov.2013, de: $<$ http://www.scielo.br/scielo.php?script=sci_arttext\&pid=S1679-

$39512011000300002 \& \operatorname{lng}=$ en\&nrm=iso $>$.

Cançado, A.C. et al.(2011) Conhecimento e produção científica nos Enapegs 2007-2010. MG: Revista APGS, 3(2). Recuperado em: 14 jul.2012, de: http://www.seer.ufv.br/seer/apgs/index.php/APGS/article/view/111/56.

(2012) Fundamentos teóricos da gestão social. Lavras: UFLA, Tese de Doutorado, 2011.

Recuperado em: 10 jul.2012, de: Disponível em:
http://gestaosocial.paginas.ufsc.br/files/2011/12/Airton-Can\%C3\%A7ado-FundamentosTe\%C3\%B3ricos-da-Gest\%C3\%A3o-Social-TeseAdmUFLA2011.pdf.

Cooper, H. M., Lindsay, J.J.(1998) Research synthesis and meta-analysis. In: Bickman, L., Rog, D. J. Handbook of applied social research methods. London: Sage Publications, 315-338. 
Filho, G.C.(2008) Definido gestão social. In: Silva Jr, J.T., Mâish, R.T., Cançado, A.C. Gestão social: práticas em debate, teorias em construção. Fortaleza: Imprensa Universitária.

Fischer, T. M D.(2002) Poderes locais, desenvolvimento e gestão - uma introdução a uma agenda. In Fischer, T. M D. (Org.). Gestão do desenvolvimento e poderes locais: marcos teóricos e avaliação. Salvador: Casa da Qualidade, 12-32.

.,Melo, V.P.(2006) Programa de desenvolvimento e gestão social: uma construção coletiva. In Fischer, T., Roesch, S., Mel, V.P. Gestão do desenvolvimento territorial e residência social: casos para ensino. Salvador: Edufba, Ciags/Ufba.

França Filho, G.C.de. (2007) Definindo gestão social. In: Encontro Nacional de Pesquisadores em Gestão Social, 1, Juazeiro do Norte (CE). Anais....

(2008) Definindo gestão social. In: Silva Jr, J. T.; Mâsih, R. T., Cançado, A. C.,

Schommer, P. C. (Orgs.). Gestão social: práticas em debate, teorias em construção. Fortaleza: Imprensa Universitária.

Freitas, A.F. de., Freitas, A.F. de., Dias, M.M.(2010) Gestão social e políticas públicas: uma mudança de abordagem no desenvolvimento rural. In: Encontro Nacional de Pesquisadores em Gestão Social, 4, Lavras (MG). Anais....

Iizuka, E.S., Sano, H.(2004) O terceiro setor e a produção acadêmica: uma visita aos Anais dos Enanpads de 1990 a 2003. RJ: In: Encontro Nacional dos Programas de Pós-graduação em Administração, Enanpad, Anais....

.(2012) Fluxo de ações, a gestão social e o processo decisório: a experiência da creche noturna em Laranjal Paulista - SP. In: Encontro Nacional de Pesquisadores em Gestão Social, 6, São Paulo (SP). Anais....

., Moraes, G.H., Salati M. de.(2013) Análise do potencial e perfil empreendedor do estudante de administração e o ambiente universitário: reflexões para instituições de ensino. São Paulo: in Anais do 8th Ibero American Academy of Management.

Lakatos, E. M \& Marconi, M. A.(2000) Metodologia científica. Editora Atlas S.A., (3 ${ }^{a}$ ed.) São Paulo.

Macedo, A. dos S., Amodeo, N.B.P., Sousa, D.N., Pinho, J.B.(2011) Gestão social em cooperativas agropecuárias: análise do trabalho de Organização do Quadro Social (OQS). In: Encontro Nacional de Pesquisadores em Gestão Social, 5, Florianópolis (SC). Anais....

Mendes, P.B.M.T.(2012) Gestão social urbana: negociação e participação de seus habitantes. In: Encontro Nacional de Pesquisadores em Gestão Social, 6, São Paulo (SP). Anais....

Mezzomo Keinert, T.(2000) O que é administração pública no Brasil. In: Encontro Anual Da Associação Nacional dos Programas de Pós-Graduação em Administração, 24, Florianópolis. Anais... Rio de Janeiro: Anpad.

Morais, S.A. de., Mendonça, P.M.E. de.(2011) A contribuição da gestão social para os desafios da gestão da sustentabilidade empresarial. In: Encontro Nacional de Pesquisadores em Gestão Social, 5, Florianópolis (SC). Anais.... 
Moreira, S.V. (2005) Análise documental como método e como técnica. In: Duarte, J., Barros, A. (Org.). Métodos e técnicas de pesquisa em comunicação. São Paulo: Atlas, 269-279.

Moura, M.B. Mendonça, M. H., Martins, S., Vieira, R. G. , Moretto Neto, L.(2012) Análise da gestão da casa do estudante da Universidade Federal de Santa Catarina sob a ótica da Cidadania Deliberativa e Gestão Social. In: Encontro Nacional de Pesquisadores em Gestão Social, 6, São Paulo (SP). Anais....

Muniz, A. da R., Onuma, F.M., Pereira, J.R.(2010) A gestão social do programa de atenção integral à Família em Lavras - MG. In: Encontro Nacional de Pesquisadores em Gestão Social, 4, Lavras (MG). Anais....

Paula, M.B. de, et al.(2010) Produção sobre terceiro setor no Brasil: pontualidade, dispersão e lacunas teóricas. RJ: In: Encontro Nacional dos Programas de Pós-graduação em Administração, Enanpad, Anais....

Pinheiro Callou, A.E., Alves, V.G.(2012) Uma visão de governança territorial inspirada em princípios de gestão social. In: Encontro Nacional de Pesquisadores em Gestão Social, 6, São Paulo (SP). Anais....

Pinho, J.A.G. de. (2010) Gestão social: conceituando e discutindo os limites e possibilidades reais na sociedade brasileira. In Rigo, A. S., Silva Júnior, J. T., Schommer, P. C., Cançado, A. C. Gestão Social e políticas públicas de desenvolvimento: ações, articulações e agenda. Recife: Univasf.

Ramos, R.R., Matos, I.M., Oliveira, L.G.L., Costa, F.J. da.(2009) Importância percebida e intenções de envolvimento com a gestão social: uma análise junto a estudantes de cursos de Administração. In: Encontro Nacional de Pesquisadores em Gestão Social, 3, Petrolina (PE) e Juazeiro (BA). Anais....

Reis, M. C. de A., Melo, F. L. B de. (2012) Participação dos atores em um fórum de gestão social para a inserção de pessoas com deficiência no mercado de trabalho: uma análise a partir das atas. In: Encontro Nacional de Pesquisadores em Gestão Social, 6, São Paulo (SP). Anais....

Schommer, P. C., França Filho, G.C. de.(2007) Gestão social e aprendizagem em comunidades de prática: interações conceituais e possíveis decorrências em processo de formação. In: Encontro Nacional de Pesquisadores em Gestão Social, 1, Juazeiro do Norte (CE). Anais....

Silva Jr, J. T. et al.(2008) Articulando diferentes metodologias de aprendizagem no ensino de gestão social na graduação: uma proposta do curso de Administração da UFC-Campus Cariri. In: Encontro Nacional de Pesquisadores em Gestão Social, 2, Palmas (TO). Anais....

Tenório, F. G.(2009) Gestão social: uma réplica. In: Encontro Nacional de Pesquisadores em Gestão Social, 3, Petrolina (PE) e Juazeiro (BA). Anais....

. (2009) Gestão social: uma réplica. Revista ADM. MADE- Revista do Mestrado em Administração e Desenvolvimento Empresarial. Rio de Janeiro: Universidade Estácio, ano 9, 13(2), 1-4, maio/agosto.

. (2008) Tem razão a administração? (3 Ed.) Ijuí: Editora da Unijuí. 
. (2005) (Re)visitando o conceito de gestão social. Desenvolvimento em Questão, 5, 101-124. Villela, L.E.(2008) Redes empresariais como germe da gestão social e do desenvolvimento local: o caso de Nova Friburgo/RJ. In: Encontro Nacional de Pesquisadores em Gestão Social, 2, Palmas (TO). Anais....

Vinha, F.D., Junqueira, L.A.P.(2011) A gestão social de uma rede do terceiro setor: o caso da rede sementeira. In: Encontro Nacional de Pesquisadores em Gestão Social, 5, Florianópolis (SC). Anais....

Data da submissão: $14 / 11 / 2012$

Data da publicação: 30/08/2013 